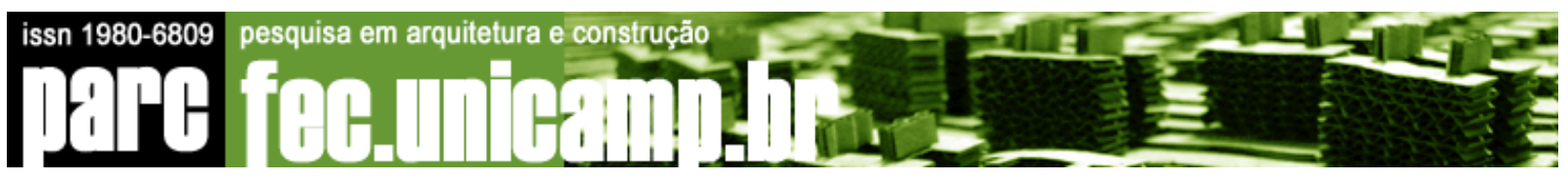

\title{
Animação como Método de Projeto
}

\section{Animation as Method of Design}

\section{EDUARDO MAROTTI CORRADI}

O autor é estudante, graduando em Arquitetura e Urbanismo pela Faculdade de Engenharia Civil, Arquitetura e Urbanismo, da Universidade Estadual de Campinas. Este artigo foi feito a partir de uma Iniciação Científica de mesmo título, no período de agosto/2007 a julho/2008, financiada pela PIBIC/CNPq, sob orientação da Profa. Dra. Gabriela Celani.

ducorradi@gmail.com

\section{Resumo}

Animação é conhecida por todos quando se trata de seu uso na indústria de entretenimento, no entanto, quando aplicado à arquitetura, até arquitetos a desconhecem. Na grande maioria dos casos, a animação na arquitetura tem sido adotada no final do processo de projeto, quando todas decisões de desenho do projeto foram tomadas, soluções para problemas arquitetônicos foram adotados.

Este artigo busca mostrar como as técnicas de animação vêm sendo utilizadas no processo de projeto, como podem auxiliar e otimizar o projeto arquitetônico, além de obter resultados dificilmente alcançados sem o seu uso.

Ao longo da pesquisa também foi desenvolvido um exercício projetual de uma instalação artística utilizando técnicas de animação, apresentando todas suas etapas de desenvolvimento.

Palavras-chave: Arquitetura; Animação; Tecnologia; Método de Projeto.

\section{Abstract}

Animation is known by everyone when we talk about the entertainment industry, however, when applied to architecture, even architects do not know it. In most of the cases, the animation used in architecture has been adopted at the end of design process, when all decisions of design have been taken, all solutions for architectural problems have been adopted.

This paper seeks to show how new animation techniques have been used in design process, how they can help and optimize the architectural project, besides to achieve results hardly obtained without its use. Along this research, a project exercise of an artistic installation was developed using animation techniques, showing all the developing stages.

Keywords: Architecture; Animation; Technology; Method of Design. 


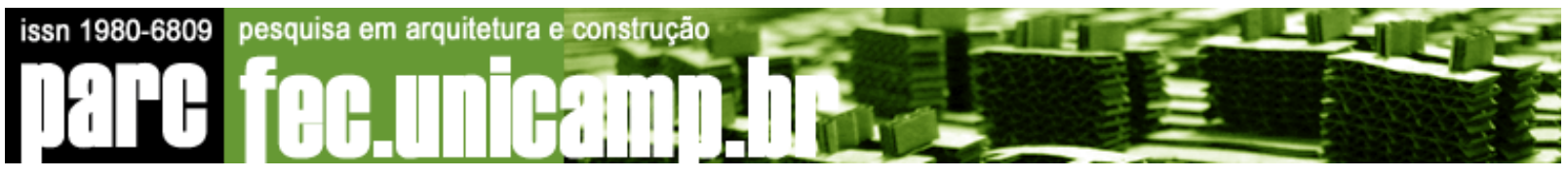

\section{Animação como Método de Projeto}

\section{Introdução}

Esta pesquisa teve como objetivo estudar o uso das técnicas de animação como ferramenta no desenvolvimento de projetos arquitetônicos. Inicialmente foi realizada uma revisão bibliográfica, sendo as principais fontes os anais de Congressos (ECAADE, Sigradi, etc), onde pode-se encontrar material sobre as diferentes aplicações dessas técnicas no processo de projeto. Tais aplicações puderam ser divididas em quatro categorias principais: representação; simulação de elementos articulados; visualização e análise de aspectos funcionais do edifício; geração de formas.

Ainda na primeira etapa foram feitas entrevistas com alguns escritórios de arquitetura e pesquisadores, relacionadas a trabalhos publicados por eles. No entanto, na segunda etapa deste projeto, estas entrevistas foram complementadas por um novo questionário que aborda questões mais amplas sobre o uso de técnicas de animação na arquitetura.

Também na segunda etapa do trabalho, foi realizado um pequeno exercício de projeto com o uso da animação como método para a geração de formas. Trata-se do projeto de uma instalação artística desenvolvida especialmente para o edifício da Faculdade de Engenharia Civil, Arquitetura e Urbanismo (FEC) da Universidade Estadual de Campinas (UNICAMP).

\section{Animação}

"Eu defino arquitetura como o encontro do espaço, evento e movimento."

Bernard Tschumi, 2001

A linguagem digital aplicada à arquitetura é algo relativamente recente, considerando o quão antiga é esta arte. O computador inicialmente não era acessível à grande parcela da população mundial - seja pelo seu custo, tamanho e utilidade - tão pouco por arquitetos, porém, na década de 80 , surge "uma segunda geração de computadores suficientemente potentes para permitir o uso de programas de CAAD e suficientemente acessíveis para serem adquiridos por escritórios de arquitetura de porte médio e pequeno. Ao mesmo tempo, uma nova geração de programas de CAAD também surgia, voltada para os grandes mercados" (CELANI, 2007). Assim, o incentivo e uso de aplicativos para arquitetura faz crescer o campo digital aplicado a ela. Nesse mesmo período surgem as associações 


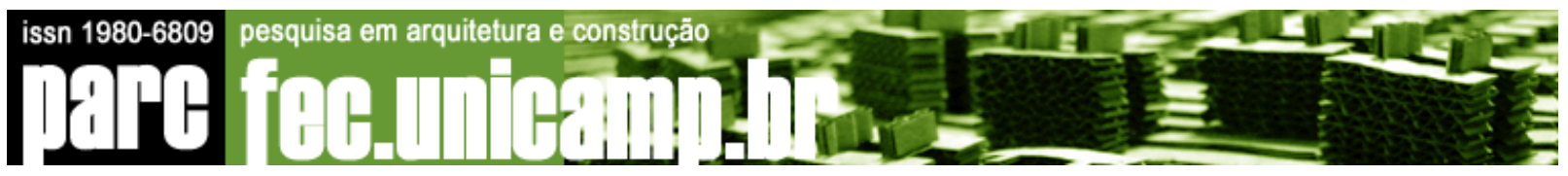

(CAADRIA, CAAD Futures, SIGRADI, eCAADe, ASCAAD) sobre o uso da computação em pesquisa e ensino para arquitetura e profissões correlatas (CELANI, 2007).

Com estas pesquisas, novas ferramentas digitais são desenvolvidas, tornando-as mais acessíveis aos usuários comuns, permitindo o contato destes com programas utilizados anteriormente apenas por campos muito específicos. Na arquitetura, o uso de novas ferramentas possibilita o desenvolvimento de novas visões, novas teorias, novos métodos projetuais.

A animação é utilizada há décadas na indústria de entretenimento - cinema, desenhos, publicidade etc. - e na última década começa a ser utilizada por uma jovem geração de arquitetos, mudando aos poucos o tão tradicional método projetual utilizado pela grande maioria dos arquitetos - predominantemente manual. As formas geométricas utilizadas por essa grande maioria - triângulos, retângulos, círculos etc. - não são as melhores formas para suportar forças externas, porém são as mais fáceis de serem executadas (KLOFT, 2001). Com técnicas normalmente utilizadas para criar animações é possível a obtenção de formas não executáveis ou representáveis pelos métodos tradicionais de desenho, criando uma nova era de projetos arquitetônicos. Animação é um “'brinquedo' sofisticado de desenho utilizado para criar mudanças morfológicas na forma arquitetônica através do movimento e reação a forças externas (ventos, chuvas, abalos sísmicos, fluxos etc)" (BENTON, 2007).

Animação, do Latim animus, significa dar vida. Animar uma imagem por exemplo, é dar vida a sua essência, dar um significado além da simples imagem que um objeto pode transmitir. Quando utilizamos animação como método projetual significa nossa vontade em simular o reflexo da vida na arquitetura em concepção.

\section{Aplicação: animação na arquitetura}

Diversas são as técnicas de animação que podem ser aplicadas à arquitetura. É possível, por exemplo, criar ambientes virtuais habitados por autômatos celulares que se movimentam por conta própria, simulando fluxos de pedestres ou veículos em um espaço. Cada autômato pode ser programado para ter um comportamento semelhante ao tipo de servivo que se quer simular. No entanto, esta é uma técnica avançada, que exige conhecimentos de programação; outro uso interessante é a animação de peças articuladas, que pode ser utilizada no projeto de coberturas e paredes retráteis, para prever seu funcionamento. Mais difundida é a técnica de visualização em que a câmera se move pelo espaço, conhecida, como walkthrough, e a técnica conhecida como panorama, um tipo de 


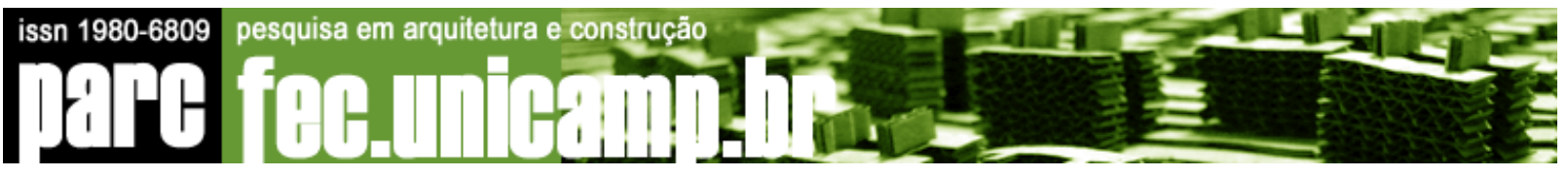

realidade virtual em que é possível rotacionar interativamente a câmera $360^{\circ}$ para visualizar um ambiente.Mais recentemente alguns arquitetos têm experimentado o uso de técnicas de animação normalmente utilizadas no desenvolvimento de filmes, como os algoritmos de animação de partículas, para a geração de formas arquitetônicas. Essa técnica, normalmente usada na animação de tecidos, líquidos, ventos etc., permite gerar formas aparentemente acidentais no projeto.

Os produtos resultantes dessas técnicas de animação podem ser agrupados em três categorias principais: as animações fixas, em que a animação é gerada uma vez (por meio de movimentação de objetos ou da câmera) e não pode mais ser alterada, como nos walkthroughs; as interativas, em que o usuário pode decidir, em tempo real em que direção a câmera deve olhar ou para onde deve se mover, como nos panoramas ou nos ambientes de realidade virtual; e as automáticas, em que algoritmos são utilizados para gerar o movimento desejado de unidades autômatas, como grãos de areia movidos pelo vento ou pessoas fugindo de um incêndio. Neste último caso o comportamento das partículas ou pessoas pode ser programado, mas sua trajetória ou movimento preciso são imprevisíveis.

As principais fontes de busca bibliográfica desta pesquisa foram os congressos de informática aplicada à arquitetura. Nota-se que o uso e a pesquisa relacionada à animação no campo arquitetônico têm aumentado ao longo dos últimos anos. Um exemplo disto foi o congresso do eCAADe de 2007, sediado em Frankfurt, onde houve uma seção exclusivamente para o tema Animação. Nesta pesquisa teve-se acesso aos anais do eCAADe 2007 e do SIGRADI 2007.

Os mais relevantes artigos encontrados relacionados ao tema fazem uso de técnicas de animação em reação a forças externas: vento, água, deslocamento de pessoas, automóveis, etc. Efeitos que provocam movimento e atingem diretamente os edifícios.

Earl Mark, em seu artigo Simulating Dynamic Forces in Design with Special Effects (2007) nos mostra como foram desenvolvidos projetos utilizando ferramentas de efeitos especiais por alunos do último ano da Escola de Arquitetura da Universidade de Virgínia, EUA. Os projetos consistiam em tendas retráteis que se expandem ao serem usadas e se retraem quando não usadas, para isso foram utilizadas técnicas de animação de simulação de tecidos para desenvolver as membranas estruturais tensionadas, e este protótipo testado com ações físicas naturais, como a gravidade e o vento. Também foi utilizada a técnica da prototipagem rápida e o modelo gerado testado em túnel de vento. No projeto de uma doca 


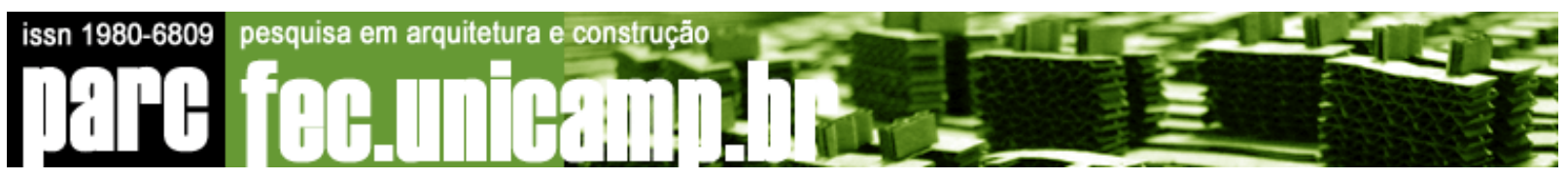

utilizado técnicas de dinâmica de fluidos. Para Mark (2007), o uso da tecnologia é "muito estimulante no processo criativo, não requer grande análise e não bloqueia o fluir das idéias".

Henriques (2007) nos mostra em três projetos como a animação foi utilizada. No Project Cyber-Eco (FIG.1) se estuda a morfologia das dunas, considerando o vento atuante, o material em movimento e o tipo de solo, cria-se um modelo no software 3dsmax e simuladas forças cinéticas e leis físicas em um sistema dinâmico utilizando gravidade e inércia, obtendo diversos modelos distintos finais sem a previsão de um resultado formal.

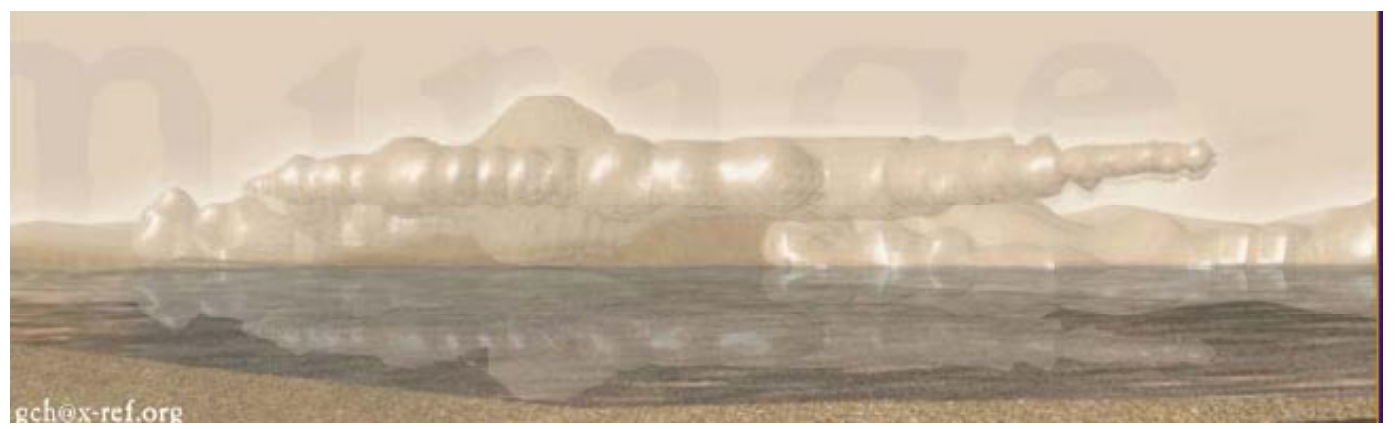

FIGURA 1. Project Cyber-Eco.

O workshop internacional Digital Design Processes, sediado em Porto (Portugal), contou com o curso Digital Morphogenesis, onde foi desenvolvido o projeto Force Fields (FIG.2): "uma oportunidade para explorar as ferramentas de animação e as incorporarem no processo de busca da forma do projeto" (HENRIQUES, 2007). Para isso foram extraídas e quantificadas forças atuantes na região da Casa da Música, na própria cidade do Porto, local de atuação do projeto. Considerou-se as relações do lugar e do contexto urbano - tráfego intenso, caminhos e limites existentes - como fatores do projeto - situação atual, possível uso do espaço público - assim, esses modificadores do espaço em constantes mudanças devido as intensidades no tempo geram forças contextuais que definem diferentes soluções para o espaço público.

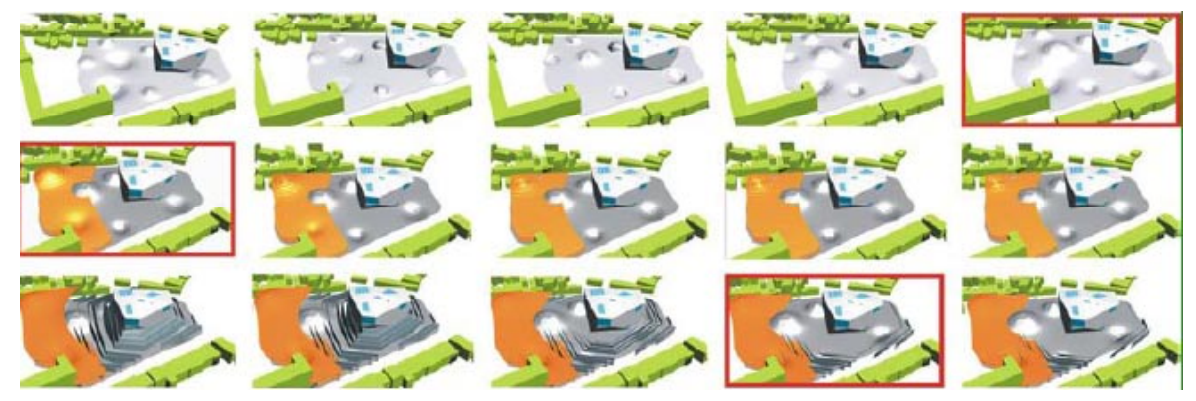

FIGURA 2. Projeto Force Fields. 


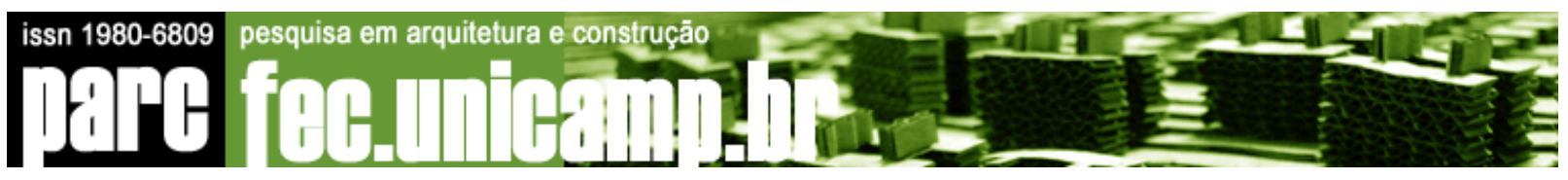

No projeto para o pavilhão da BMW Dynaform, de Bernhard Franken, em Frankfurt, foram utilizadas técnicas de animação baseado em forças de aceleração. Simulou-se o movimento de carros da série 7 da BMW afim de traduzir o efeito de plasticidade e dinamismo da linha para o projeto arquitetônico (FRANKEN, 2001). O processo de projeto iniciou-se com um briefing de estudos, traduzido para um processo paramétrico, obtendo uma geometria digital. A partir de uma malha, considerando as forças repulsivas de edifícios do entorno, simulou-se o movimento dos carros dentro desta malha, deformando-a, obtendo a forma principal do projeto. Nesta primeira etapa foi utilizado o software de modelagem 3D e animação Maya. Em uma segunda etapa foram utilizados programas como Rhinoceros e AutoCAD para planificação da estrutura, assim como para a repetição paramétrica da forma principal. O projeto final é composto por diversas derivações dos estágios digitais, todos obtidos a partir da forma principal (FIG.3) (FRANKEN, 2001).

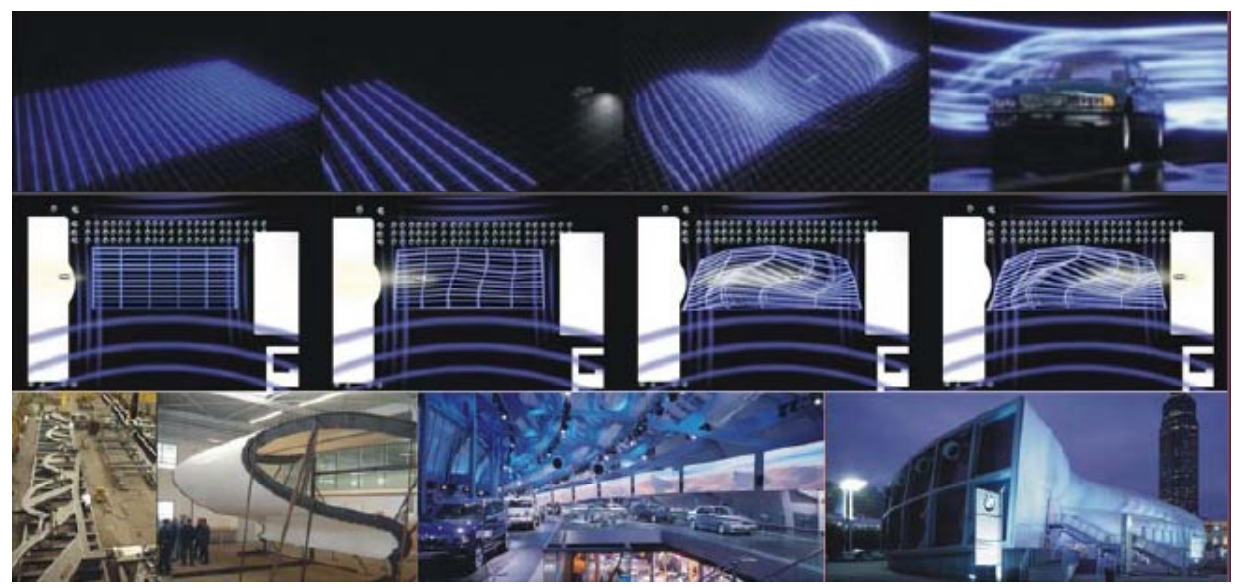

FIGURA 3. Projeto do pavilhão BMW Dynaform.

Soza e Domke apresentaram no SIGRADI 2007, realizado no México, o artigo Morfología Evolutiva: dos aproximaciones proyectuales, onde se utilizou o movimento de um bípede (FIG.4) para gerar a forma desejada. Para isso, durante o movimento do bípede eram marcados os principais pontos da trajetória selecionando seus keyframes ${ }^{1}$ - "talvez a mais importante decisão a ser tomada no desenho do projeto" (SOZA, 2008) - a fim de montar a curva NURBS² desejada. 

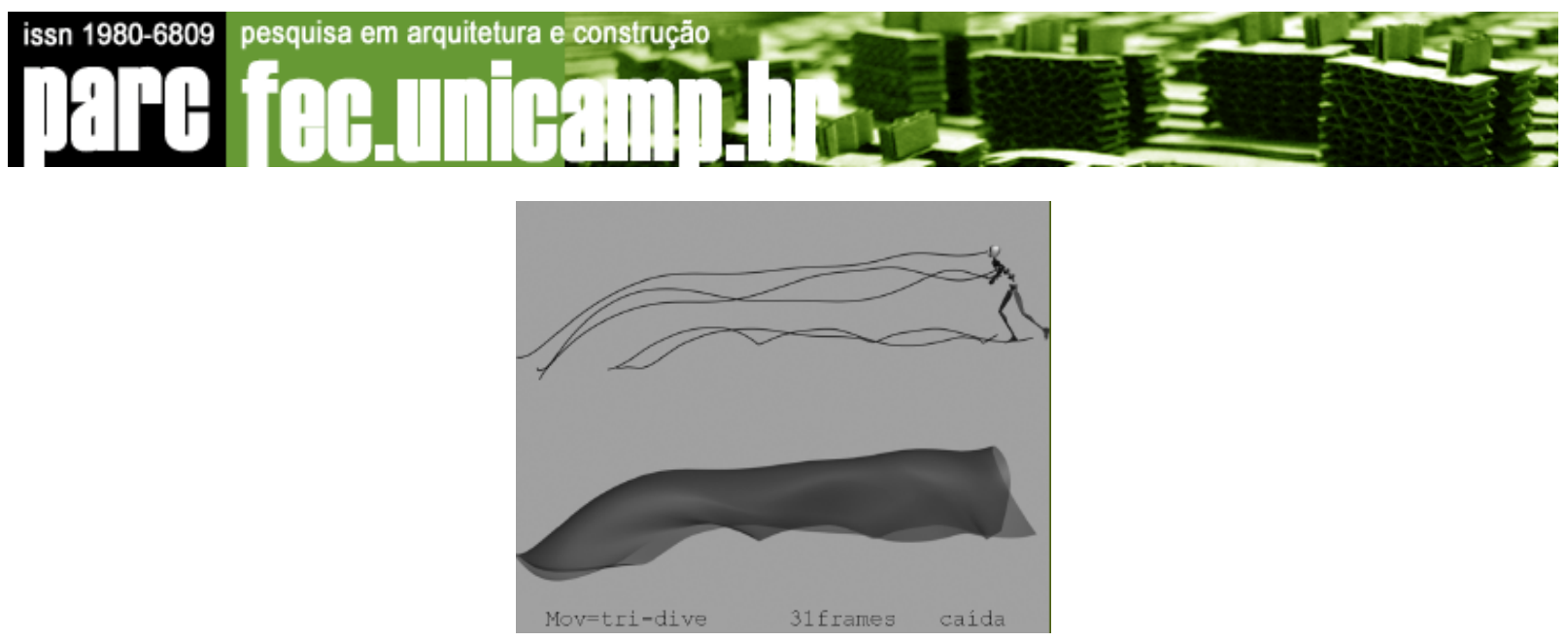

FIGURA 4: Estudo do movimento do bípede.

No entanto, outros tantos artigos mostram como a animação pode ser utilizada no desenvolvimento do projeto sem que o movimento ou forças externas sejam geradores da forma.

Narahara (2007) mostra em seu artigo The Space Re-Actor " um método computacional que visualiza reações humanas em relação a condições físicas descritas em um modelo arquitetônico sintético" (Narahara, 2007). Para isso, utilizou-se agentes ${ }^{3}$ (bípedes) do software 3dsmax com programação de comportamento feita pelo software NetLogo e inserida nos bípedes pelo maxscript ${ }^{4}$ por arquivos .txt gerados para cada agente com todas as informações das coordenadas x e y" (NARAHARA, 2008), o que criou as trajetórias para os bípedes e quando o maxscript encontra códigos ascii (responsáveis pelo comportamento dos bípedes) gera as ações as quais está programado (sentar, andar, conversar, comer etc.) (NARAHARA, 2008). Com o uso deste método se pode enxergar as falhas do projeto ocupado por pessoas antes mesmo dele ser construído, provendo grandes melhorias a ele.

No artigo SAFDE - Sadness, Anger, Fear, Disgust, Enjoyment, Serrato-Combe (2007) mostra a experiência em sala de aula onde cada aluno desenvolvia uma animação criando modelos arquitetônicos fantásticos sem a intenção de que esse possa ser executado, apenas para tentar passar algum sentimento para quem os vê, explorando o uso de diversas formas geométricas, cores, movimento etc..

Diversos artigos mostram como vem sendo bastante utilizado a realidade virtual, principalmente na reconstrução de ambientes históricos. Ambientes de realidade virtual também podem ser criados na fase de desenvolvimento do projeto, permitindo que se tenha uma noção mais apurada da escala do projeto, iluminação, percursos possíveis, etc., com elevado grau de interatividade. 


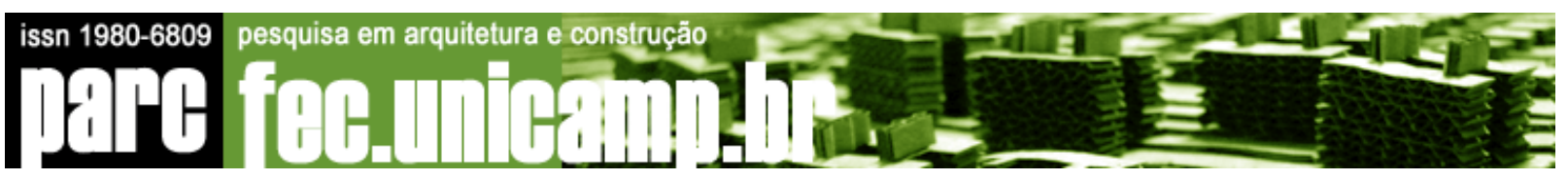

\section{Entrevistas}

A partir da leitura de diversos artigos, procurou-se entrar em contato com seus autores a fim de obter informações mais detalhadas sobre suas pesquisas. Na primeira etapa desta pesquisa, entrou-se em contato com Pedro Soza, Taro Narahara e Bernhard Franken para maiores esclarecimento sobre seus artigos ${ }^{6}$.

Em uma segunda etapa elaborou-se um questionário padrão a fim de entrevistar arquitetos e pesquisadores ligados ao tema abordado por esta pesquisa. O questionário foi elaborado de maneira a englobar questões tanto de crítica de arquitetura quanto de aspectos mais técnicos sobre os projetos por eles desenvolvidos:

1. Você poderia citar algumas obras suas que exemplificam o uso da animação no desenvolvimento de projeto? Quais técnicas foram utilizadas?

2. Quais as vantagens em se desenvolver projetos utilizando técnicas de animação em relação às desenvolvidas por métodos tradicionais, ou seja, aqueles que utilizam CAD simplesmente para representação? Quais ideias são possíveis expressar utilizando essas técnicas?

3. Como são vistas essas novas técnicas de desenvolvimento de projecto por críticos de arquitectura, por arquitectos, pela nova geração de estudantes de arquitectura e pelos leigos?

4. Estes projectos que usam essas novas técnicas, como a animação, ainda estão em uma fase experimental ou já podem ser inseridos em um contexto urbano como outros edifícios tradicionais, que seguem a linguagem urbana existente? Quais os impactos deste tipo de projeto na imagem da cidade contemporânea?

5. A tendência da arquitetura dos próximos anos é se apoiar em novas tecnologias para a geração de formas e abandonar aos poucos os métodos mais tradicionais?

As entrevistas foram encaminhadas para Bernard Tschumi, Taro Narahara, Bernhard Franken, Gonçalo Castro Henriques, NOX, Asymptote, Pedro Soza, Mark Burry, Gregory More, Kas Oosterhuis, Ali Rahim, Timothy Durfee, Mark Goulthorpe e Pia Ednie-Brown. No entanto, obteve-se respostas apenas de Berthold Scharrer, do escritório de Bernhard Franken, Taro Narahara e Gonçalo Castro Henriques ${ }^{7}$. 


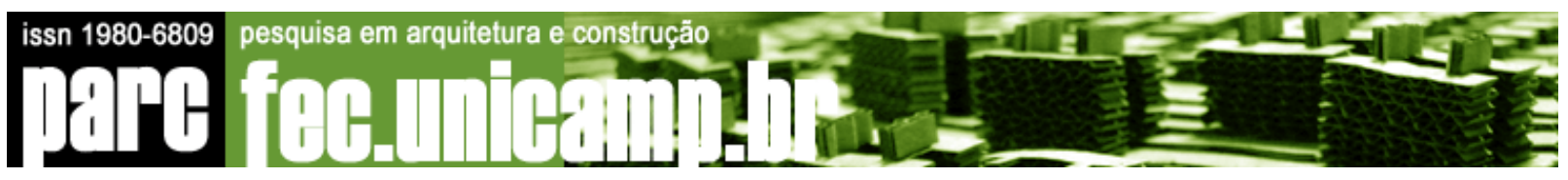

Segundo Henriques (2008), as técnicas de animação são "uma forma de expandir a capacidade de concepção do projeto". O arquiteto português diz ter usado a animação computacional em alguns projetos seus, como GeneticLandscape (FIG.5 e 6), Cyber-Eco Fusion e Evolutionary Strategies for Design, e afirma que as técnicas usadas podem ser as mais variadas, não havendo "uma receita prévia a ser seguida". Tal como Henriques, Franken utilizou técnicas de animação no desenvolvimento de alguns de seus projetos como Home Couture, BMW Bubble (FIG.7), BMW Take-Off (FIG.8), Dynaform (BMW Pavillion) e BMW X6 Superspace. Com uma outra visão, Narahara enxerga as técnicas de animação como uma boa plataforma de visualização do comportamento humano dentro do edifício, como em seu trabalho The Space Re-Actor, em que utilizou automatos celulares para simular fluxos (FIG.9 e 10).


FIGURAS 5 e 6. Projeto GeneticLandscape, em fase de construção e concluído. Fonte: HENRIQUES (2008). 

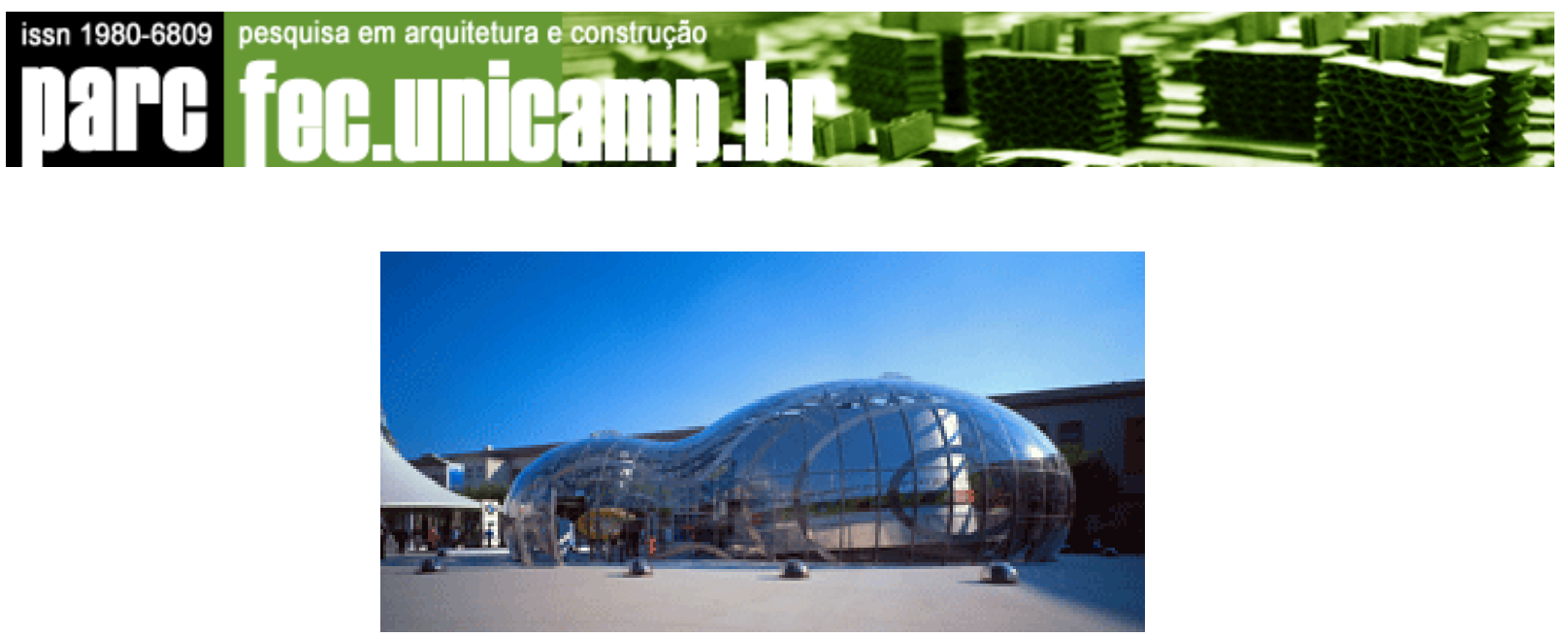

FIGURA 7. Projeto BMW Bubble. IAA Frankfurt, 1999.

Fonte: www.daz.de

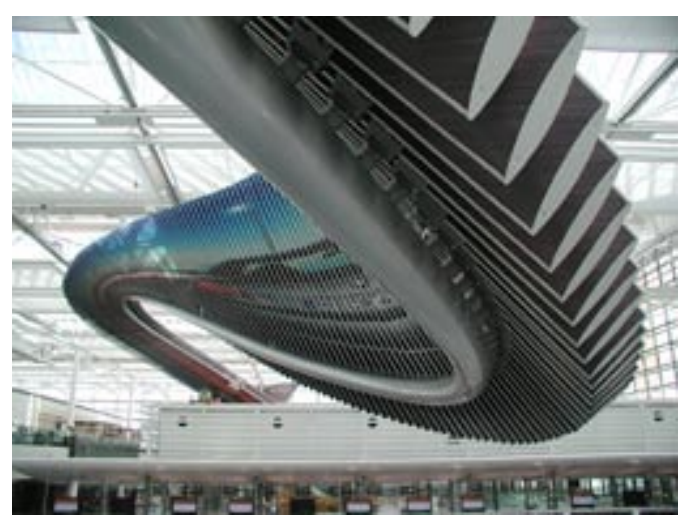

FIGURA 8. Projeto BMW Take-Off. Aeroporto de Munique, 2003.

Fonte: www.daz.de
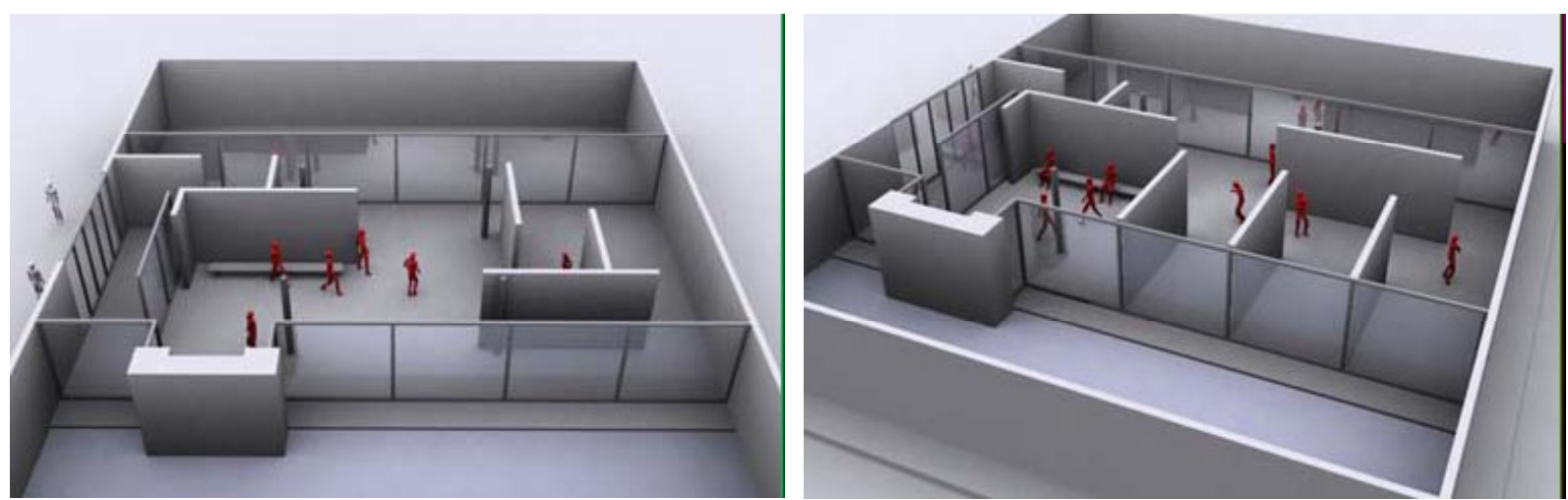

FIGURAS 9 e 10. Projeto The Space Re-Actor.

Fonte: NARAHARA, Taro (2007)

Os três entrevistados vêem o uso de técnicas de animação no desenvolvimento de projetos com um olhar bastante otimista, pois com a utilização de técnicas de animação "é possível desenvolver projetos em que a forma é vista como um elemento dinâmico, inserido 


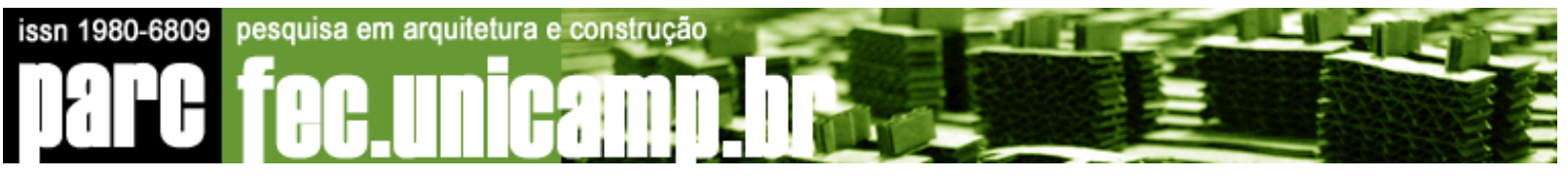

no tempo e num contexto capaz de a gerar" (HENRIQUES, 2008). Segundo Narahara (2008), como "o crescimento da cidade ao longo do tempo, o comportamento de habitantes dentro de um edifício, edifícios em construção etc." pode ser previsto por meio da animação. Técnicas de animação ainda "abrem caminhos e novos potenciais no planejamento e eficiência de produção para o novo vocabulário arquitetônico que se adapta a processos e representa o espírito de pessoas criativas" (SCHARRER, 2008).

Segundo Scharrer (2008), a aceitação e reconhecimento do uso de técnicas de animação no desenvolvimento de projetos "depende de que partido cada pessoa pertence", ou seja, se é bem vista, e claro, defendida por pesquisadores e arquitetos que desenvolvem projetos baseados em tais técnicas, sendo por vezes "vistos com desconfiança por críticos" (HENRIQUES, 2008), "que criticam as abordagens iniciais mais utópicas que levaram a que a palavra virtual ganhasse uma conotação negativa e perdesse a relevância que filosoficamente adquiriu" (HENRIQUES, 2008), no entanto são aceitas com entusiasmo pelos estudantes, pois essas "tecnologias das novas mídias já fazem parte do seu dia-a-dia" (HENRIQUES, 2008). Narahara (2008) expõe a importância da animação como ferramenta de análise e visualizção, pois é "muito mais intuitiva e comunica melhor complexas idéias tridimensionais sem considerar o nível de entendimento do espectador sobre o espaço".

A arquitetura existente hoje em nossas cidades (arquitetura modernista) impõe muitas restrições aos usuários, e as formas livres (blob architecture) prometeram trazer uma outra realidade (HENRIQUES, 2008), no entanto "é necessário bom senso e sensibilidade para poder analisar a questão nos vários aspectos envolvidos, como seja o social, psicológico, cultural e humano" (HENRIQUES, 2008). Ações de reuso e alterações de estruturas existentes nas cidades são cada vez mais comuns no mundo contemporâneo, e as novas tecnologias de mídia são promissoras e modelos potencialmente econômicos para 0 enriquecimento arquitetônico da cidade contemporânea sem construções caras (NARAHARA, 2008). Para Scharrer (2008), cada caso deve ser visto isoladamente, pois ao integrar formas geradas em um contexto urbano existente, estas se apresentam individualmente como interpretações boas ou ruins das possibilidades arquitetônicas atuais. O arquiteto conclui ainda que elas não substituem a ação integral do homem, mas apresentam diferentes possibilidades para abordar problemas existentes.

Narahara (2008) acredita que as diferentes ferramentas existentes hoje que auxiliam no desenho e execução de projetos (CAD software, prototipagem-rápida, etc.) nos permitem criar formas mais complexas e fabricá-las, o que não era possível há alguns anos atrás. Acha 


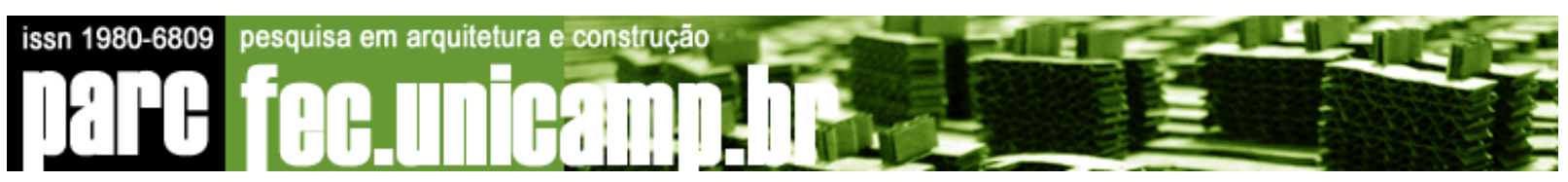

também que novas ferramentas ainda serão usadas com o intuito de criar edifícios com performances e funcionalidades fundamentalmente inovadoras. Para Henriques (2008) "estamos num momento em que, por serem novas, estas tecnologias oferecem grandes possibilidades, mas a tecnologia necessita de respostas locais para poderem ser absorvidas e integradas com as tecnologias tradicionais e assim desempenharem o seu papel". Scharrer (2008) diz que o ponto principal não é a geração de formas, mas o uso das tecnologias para se aprofundar os pensamentos em complexas relações, o que resulta na forma gerada".

\section{Geração de formas}

Ao longo desta pesquisa, diversas técnicas de animação, que pudessem ser aplicadas como instrumentos geradores de formas arquitetônicas, foram identificadas e testadas.

Técnicas como movimentação de biped, simulação de partículas, colisões, ações físicas naturais etc. foram testadas. Para isso foi utilizado o software de modelagem e animação 3dsMax 9, da empresa Autodesk e algumas ferramentas do software necessárias para cada técnica aqui mencionada.

Para melhor compreensão das técnicas utilizadas e comparação de suas dificuldades de manipulação e resultados que podem ser atingidos com seus usos, foi criado um resumo (TAB.1) a fim de sistematizar todos os dados obtidos após análises dos testes.

As técnicas testadas foram aquelas consideradas mais adequadas à geração de formas em arquitetura, porém existem diversas outras técnicas, tais como simulação de líquidos, campos de força, colisões que geram deformações etc. Algumas dessas técnicas exigem o uso de software e plugin específicos, tais como RealFlow e Glu3D. 


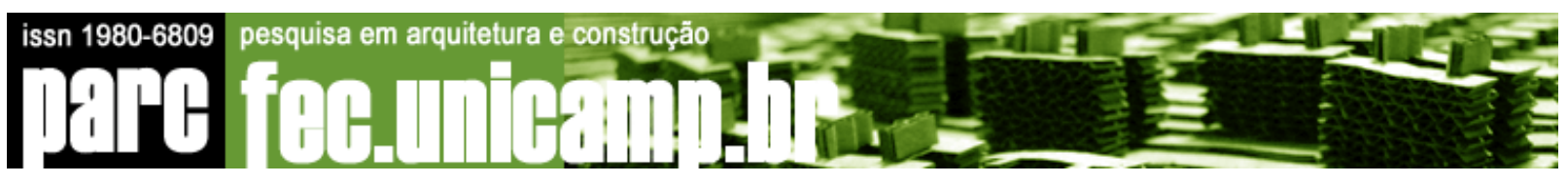

\begin{tabular}{|c|c|c|c|c|}
\hline TÉCNICA & EFEITO & FERRAMENTAS & NÍVEL DE DIFICULDADE & NÍVEL DE CONTROLE \\
\hline $\begin{array}{l}\text { Simulação de } \\
\text { Partículas }\end{array}$ & $\begin{array}{l}\text { Dissolução de } \\
\text { objetos } \\
\text { (Fig. 11) }\end{array}$ & $\begin{array}{l}\text { - Particle Flow } \\
\text { - Drag (SpaceWarps) } \\
\text { - Gravidade } \\
\text { - Vento }\end{array}$ & $\begin{array}{c}\text { ALTO } \\
\text { muitos parâmetros a } \\
\text { serem configurados para } \\
\text { controlar a emissão de } \\
\text { partículas }\end{array}$ & $\begin{array}{c}\text { BAIXO } \\
\text { apesar de saber qual a } \\
\text { direção do vento e a força } \\
\text { de gravidade, não é } \\
\text { possível definir como as } \\
\text { partículas se movimentam }\end{array}$ \\
\hline $\begin{array}{l}\text { Simulação de } \\
\text { Partículas }\end{array}$ & $\begin{array}{l}\text { Colisão e quebra } \\
\text { de objetos } \\
\text { (Fig. 12) }\end{array}$ & $\begin{array}{l}\text { - PArray } \\
\text { - PBomb (Force - } \\
\text { SpaceWarps) } \\
\text { - Gravidade }\end{array}$ & $\begin{array}{c}\text { ALTO } \\
\text { muitos parâmetros a } \\
\text { serem configurados para } \\
\text { controlar o } \\
\text { comportamento das } \\
\text { partículas após colisão }\end{array}$ & $\begin{array}{c}\text { BAIXO } \\
\text { apesar de saber qual a } \\
\text { direção do vento e a força } \\
\text { de gravidade, não é } \\
\text { possível definir como as } \\
\text { partículas se movimentam }\end{array}$ \\
\hline $\begin{array}{l}\text { Simulação de } \\
\text { ações físicas } \\
\text { naturais }\end{array}$ & $\begin{array}{l}\text { Movimentação de } \\
\text { tecidos por vento } \\
\text { e gravidade } \\
\text { (Fig. 13) }\end{array}$ & $\begin{array}{l}\text { - Reactor } \\
\text { (Gravidade, Vento, } \\
\text { RBCollection, } \\
\text { Reactor Cloth) }\end{array}$ & $\begin{array}{c}\text { MÉDIO } \\
\text { apesar de necessitar da } \\
\text { configuração de muitos } \\
\text { parâmetros, estes são } \\
\text { conhecidos, como } \\
\text { velocidade do vento, } \\
\text { oscilação de sua } \\
\text { intensidade etc. }\end{array}$ & $\begin{array}{c}\text { BAIXO } \\
\text { apesar de saber qual a } \\
\text { direção do vento e a força } \\
\text { de gravidade, não é } \\
\text { possível definir como o } \\
\text { tecido vai reagir às } \\
\text { oscilações da intensidade } \\
\text { do vento; depende } \\
\text { também da densidade do } \\
\text { tecido } \\
\end{array}$ \\
\hline Biped & $\begin{array}{c}\text { Movimentação de } \\
\text { pessoas }\end{array}$ & - Biped System & $\begin{array}{c}\text { BAIXo } \\
\text { o processo é fácil, no } \\
\text { entanto trabalhoso para } \\
\text { criar todo percurso e } \\
\text { movimentação do } \\
\text { esqueleto e } \\
\text { transformação de seu } \\
\text { percurso em forma } \\
\text { definida }\end{array}$ & $\begin{array}{c}\text { ALTO } \\
\text { mesmo que o movimento } \\
\text { do biped seja aleatório, } \\
\text { ao escolher os pontos } \\
\text { para gerar linhas NURBS } \\
\text { e conseqüentemente a } \\
\text { superfície, induz-se a um } \\
\text { resultado desejado }\end{array}$ \\
\hline
\end{tabular}

TABELA 1. Quadro comparativo entre as técnicas de animação testadas na pesquisa

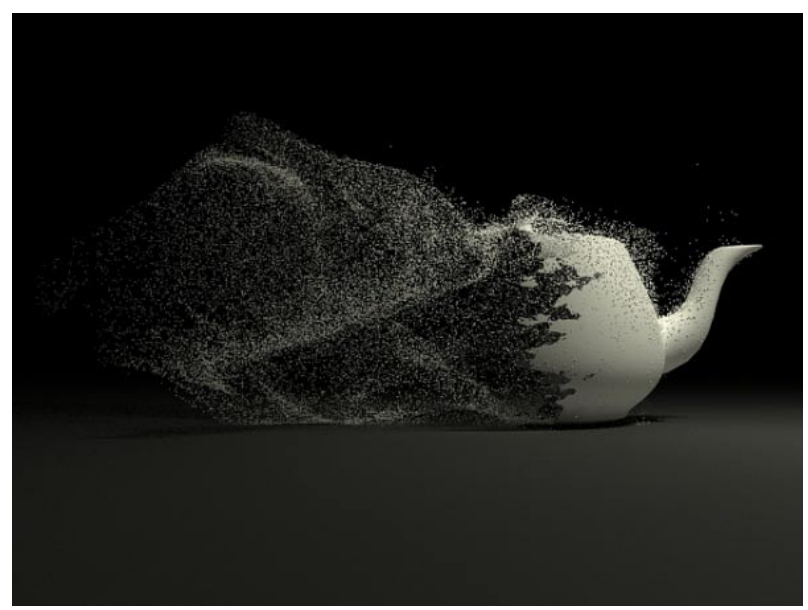

FIGURA 11. Dissolução de um objeto - partículas criam um novo volume aleatório Teste realizado pelo autor. 

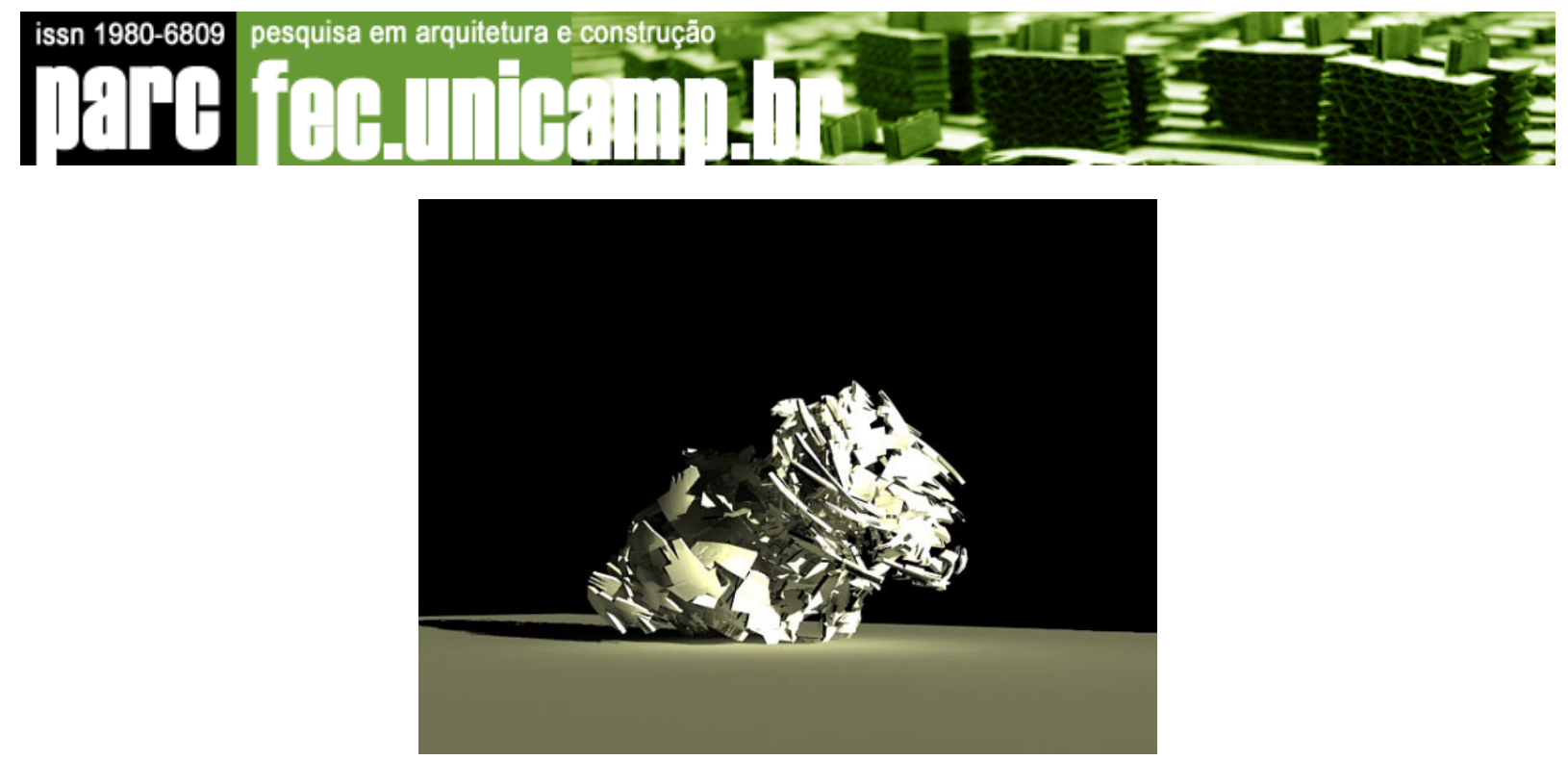

FIGURA 12. Colisão e conseqüente quebra do objeto, desfragmentando-se em diversas partes. Teste realizado pelo autor.

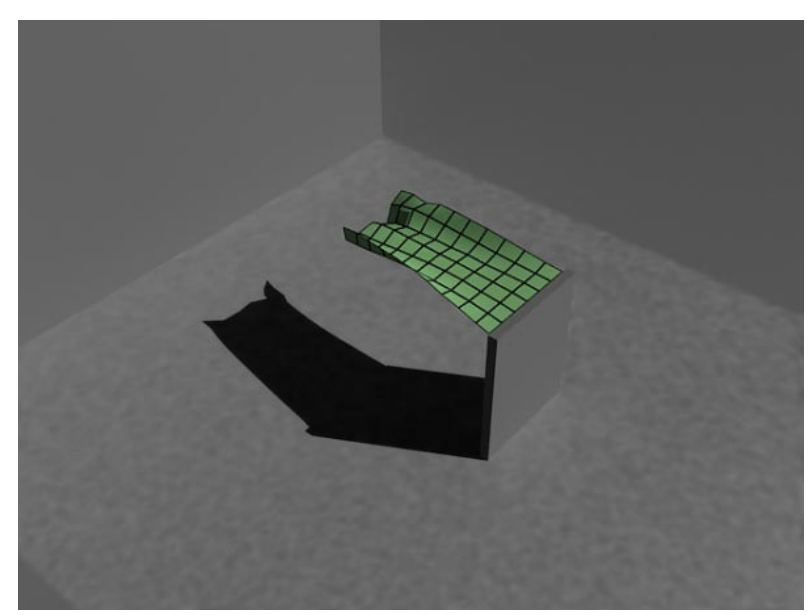

FIGURA 13. Tecido é sacudido sob ação do vento e gravidade. Teste realizado pelo autor.

Além da geração de formas com o uso da animação, esta pesquisa teve também uma preocupação em estudar como uma forma fluida, gerada por efeitos de animação, poderia ser efetivamente construída. Para isso, foi utilizado um programa especialmente desenvolvido para gerar estruturas para formas orgânicas, o Paracloud. Foram também utilizadas técnicas de fabricação digital, que permitem a produção de maquetes e elementos construtivos com grande nível de complexidade, diretamente a partir dos arquivos digitais. As técnicas de fabricação digital encontram-se disponíveis no Laboratório de Automação e Prototipagem para Arquitetura e Construção (LAPAC) da Faculdade de Engenharia Civil, Arquitetura e Urbanismo (FEC). 


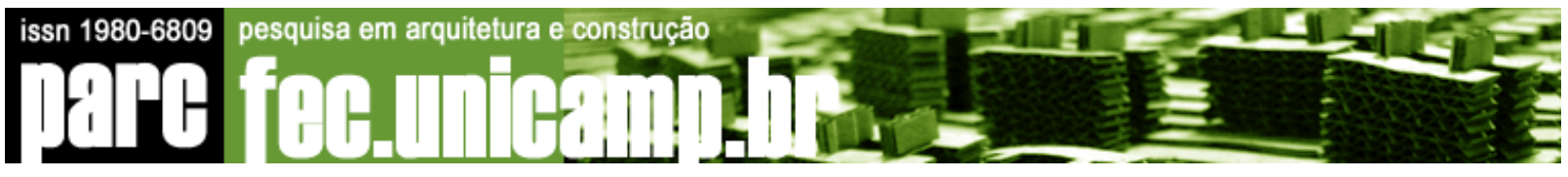

\section{Projeto}

Optou-se por fazer um exercício projetual bastante simples, a partir da análise do local escolhido, uma passagem no pavimento térreo do edifício da FEC que liga o pátio da cantina ao estacionamento. O local é apelidado pelos alunos da faculdade de "túnel de vento", uma vez que, nos dias em que há muito vento, uma forte corrente de ar percorre o corredor. Com o objetivo de acentuar essa característica do espaço, imaginou-se uma situação em que um grande lençol seria pendurado ao longo das paredes e teto do corredor, e sacudido violentamente pelo vento.

Assim, o projeto foi desenvolvido em quatro etapas, a saber:

(1) Modelagem geométrica do edifício e do tecido; criação da animação no software 3dsMax, com a utilização do plug in Reactor, e identificação do quadro (frame) da animação, que melhor representava o conceito do projeto (quadro 68);

(2) Importação do modelo geométrico do quadro escolhido para o software Rhino e conversão da superfície em uma malha;

(3) Geração de uma estrutura de costelas sobre a malha, com o uso do software Paracloud, e planificação da estrutura para corte;

(4) Produção de uma maquete em acrílico e MDF, em escala 1:25, com o uso de uma cortadora a laser.

Para a simulação da distorção do lençol que cobria o corredor (com dimensões de $3 \mathrm{~m}$ de altura, $3 \mathrm{~m}$ de largura e $9 \mathrm{~m}$ de comprimento) sob forte ação do vento e gravidade foram colocados planos (plane) nas superfícies das paredes e tetos, prendendo suas extremidades ao edifício. Em seguida, foram aplicados o modificador Reactor Cloth e adicionado ao CLCollection do Reactor, fazendo com que o plane tenha características de um tecido. Para não penetrar no volume do edifício, este foi adicionado ao RBCollection do Reactor, conferindo-Ihe características de um corpo rígido (Rigid Body). O vento (Wind do Reactor) foi posicionado de maneira que o vento cruzasse o sentido longitudinal do corredor. Dessa maneira a animação foi criada utilizando o mundo Havock1 do Reactor, configurando alguns de seus parâmetros a fim de obter resultados o mais próximo possível da realidade (FIG.14). A animação foi criada com 300 quadros (10 segundos), porém notou-se que a maior variação no tecido ocorre até o quadro 150. Depois disso sua variação passa a cer cíclica. Assim, escolheu-se o quadro 68 como o mais representativo do que se buscava mostrar com esse trabalho, o movimento.

\section{http://WWW.fog.unibamp.hr/ part}



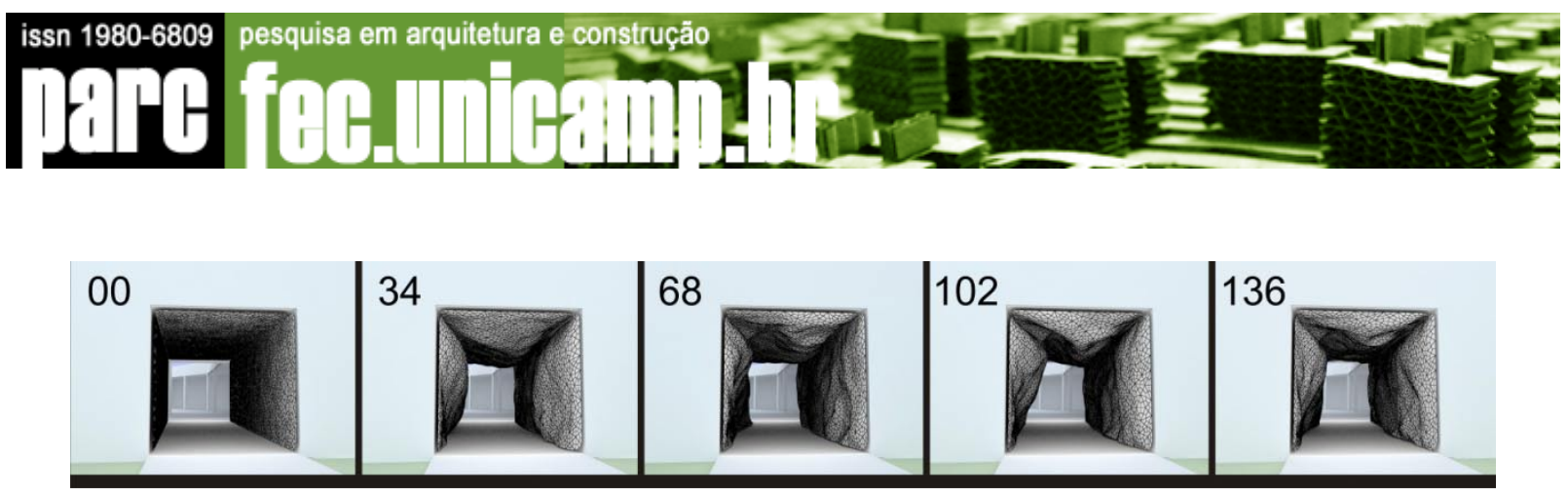

FIGURA 14. Quadros da animação mostrando um grande lençol sendo sacudido pelo vento no corredor do edifício.

Tendo em vista que seria criada uma estrutura em costelas (Rib Structure) para o projeto desenvolvido, com o auxílio do software Paracloud, foi necessário transferir a forma obtida no 3dsmax para o Rhino (FIG.15), uma vez que o Paracloud não interage com o 3dsmax. Assim, como o Rhino não reconhecia a forma criada no 3dsmax, foram feitas várias secções desta forma ainda no 3dsmax e contornadas com curvas NURBS. Porém, o Rhino ainda não reconhecia a forma como superfície (geometria necessária para ser lida pelo Paracloud), então novamente, no próprio Rhino, as NURBS originais do 3dsmax foram contornadas por NURBS do Rhino e a partir delas gerada uma superfície por meio do comando Loft. Foram feitas dezoito subdivisões da malha, em ambos os sentidos, para que cada quadrante da superfície tivesse em média $50 \times 50 \mathrm{~cm}$ (em escala real), pois a geração da estrutura no Paracloud se baseia nessas divisões.

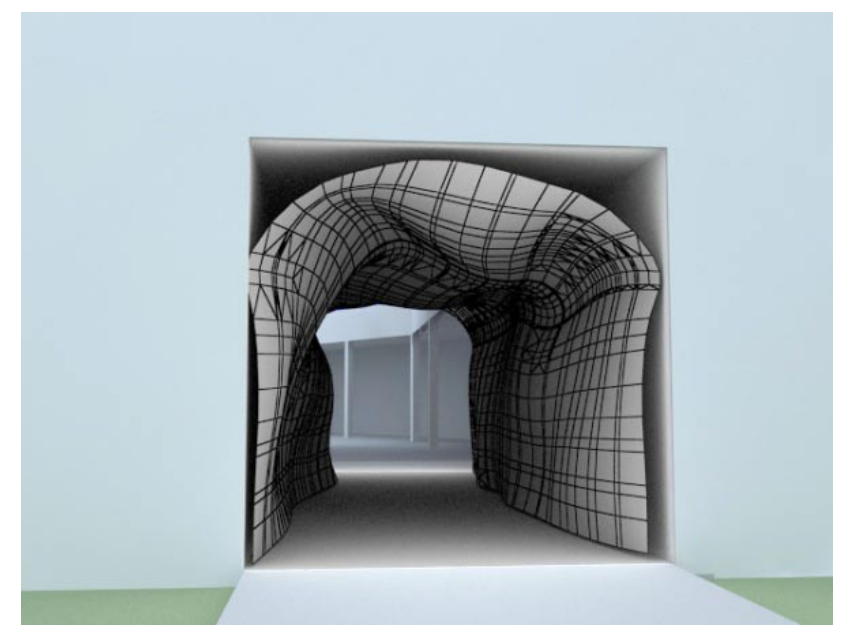

FIGURA 15. Superfície obtida no 3dsmax e convertida com NURBS no Rhino.

Uma vez criada a superfície necessária para ser usada no Paracloud, inicou-se o processo de criação da estrutura em costelas do projeto (Rib Structure). Em uma primeira etapa todos os processos estavam corretos, porém notou-se que a escala do modelo estava errada. Após a mudança de escala, diversos erros surgiram ao gerar a estrutura. Deste

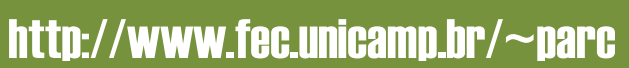




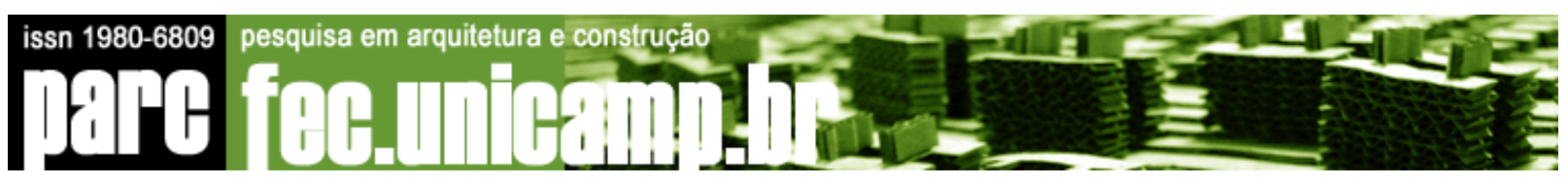

modo, entrou-se em contato diversas vezes com o desenvolvedor do software, Eyal Nir, afim de tentar solucionar o problema citado, pois por se tratar de um software novo e ainda pouco conhecido, não se encontra material de apoio além daquele fornecido pelo autor do software em seu próprio site ${ }^{8}$. Após diversas conversas com o desenvolvedor do Paracloud, por meio de troca de emails e Skype, o problema foi resolvido, exportando a estrutura gerada para o Rhino e posteriormente para o 3dsmax, para ser inserido no corredor do edifício (FIG. 16 e 17).

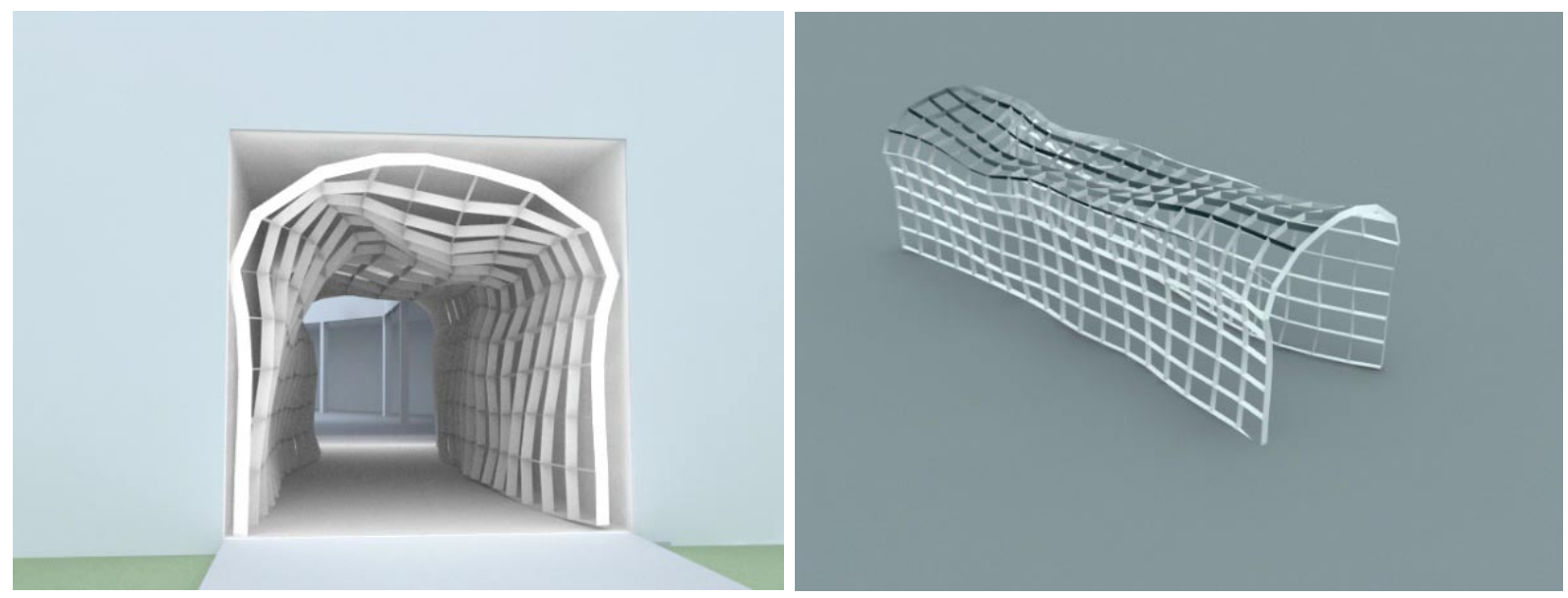

FIGURAS 16 e 17. Rib Structure geradas pelo Paracloud a partir de superfície do Rhino.

Com os modelos virtuais criados, foi desenvolvido um modelo físico do projeto, em escala 1:25, utilizando chapa de MDF de $3 \mathrm{~mm}$ de espessura para representar a estrutura, chapas de acrílico de $2 \mathrm{~mm}$ de espessura para formar o corredor, a fim de possibilitar a visualização por completo da estrutura, e uma base de MDF de $6 \mathrm{~mm}$ de espessura pintada de preto para dar mais destaque à estrutura.

O próprio Paracloud gera toda a planificação da estrutura e a exporta para o Rhino (FIG. 18 e 19), primeiramente as de um sentido e depois as de outro, além de criar os nós de encaixe entre as peças e sua numeração (Fig. 20 e 21), facilitando a montagem do modelo. Esse desenho foi exportado para o AutoCAD para que pudesse ser cortado pela cortadora a laser do LAPAC, uma X-660 da Universal Laser Systems. 

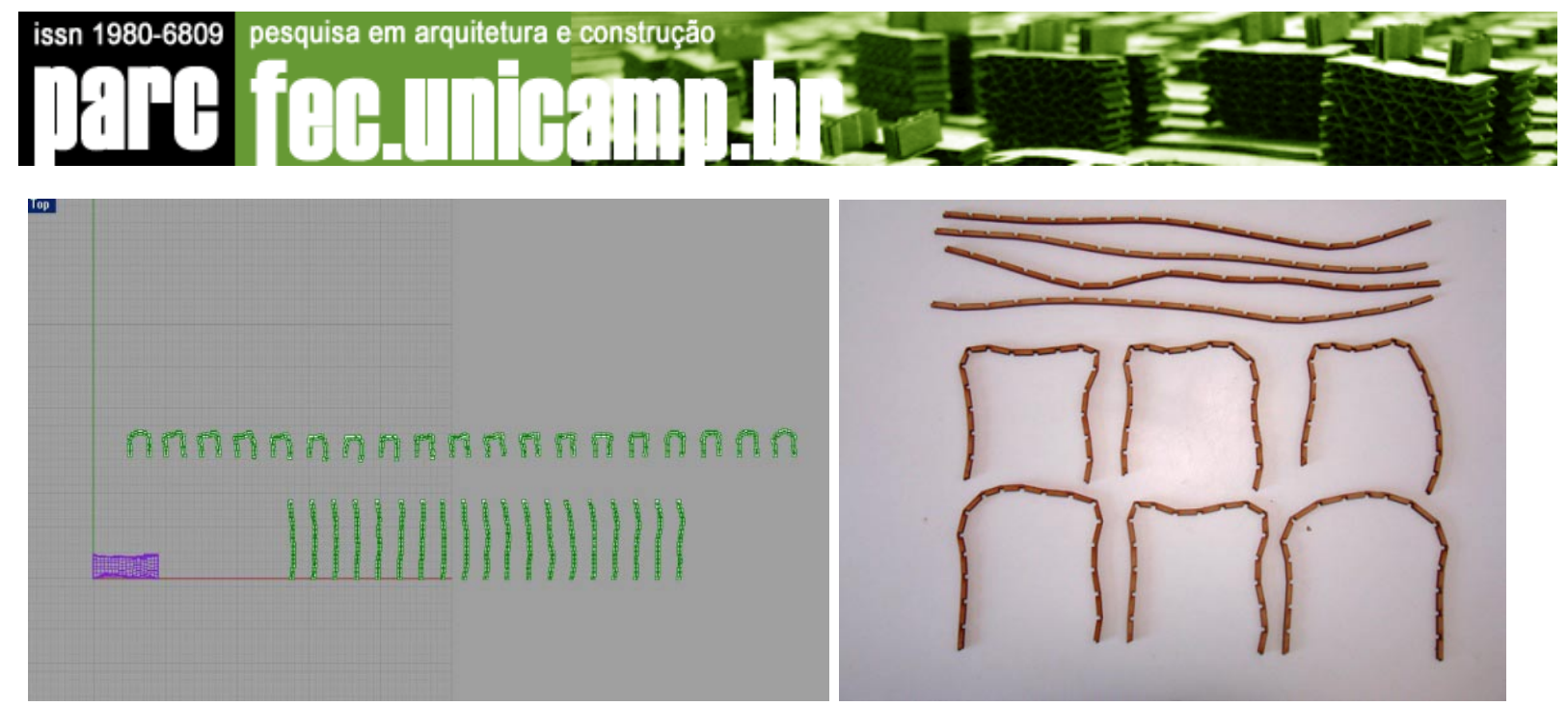

FIGURAS 18 e 19. Peças da estrutura planificadas no Rhino e cortadas.
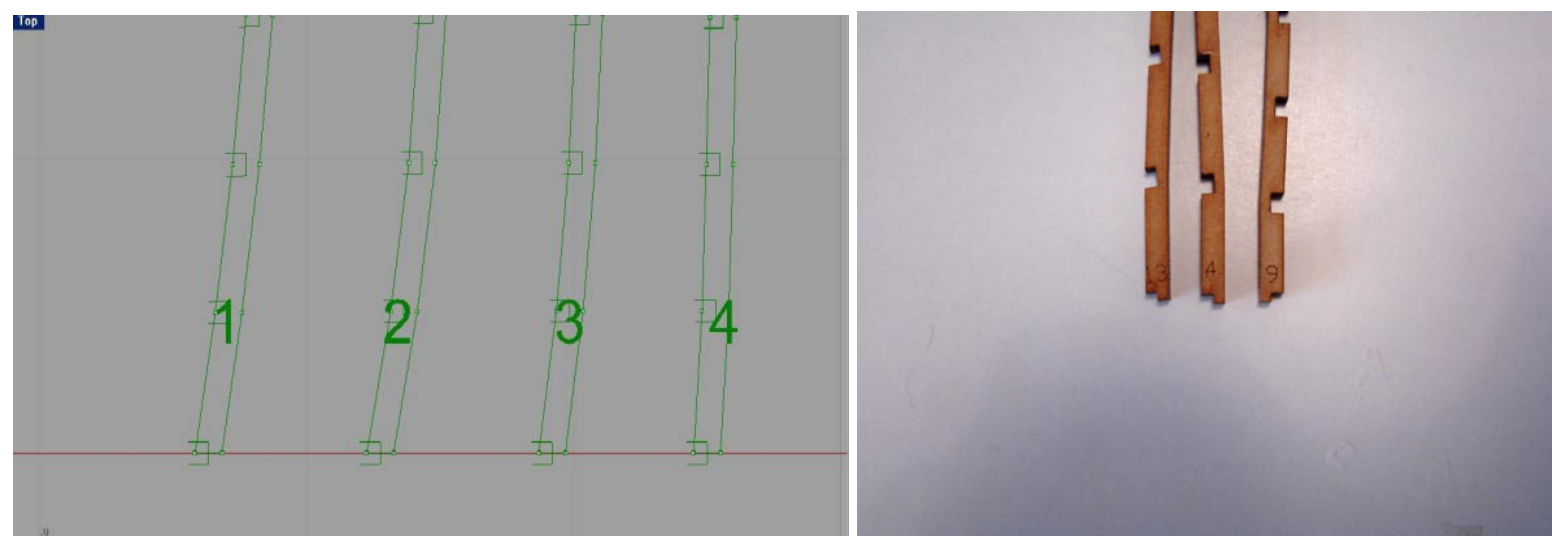

FIGURAS 20 e 21. Encaixes e numeração das peças da estrutura no Rhino e cortadas.

Com todas as peças cortadas e um total de 361 encaixes, montou-se o modelo físico do projeto proposto (FIG. 22, 23, 24 e 25).
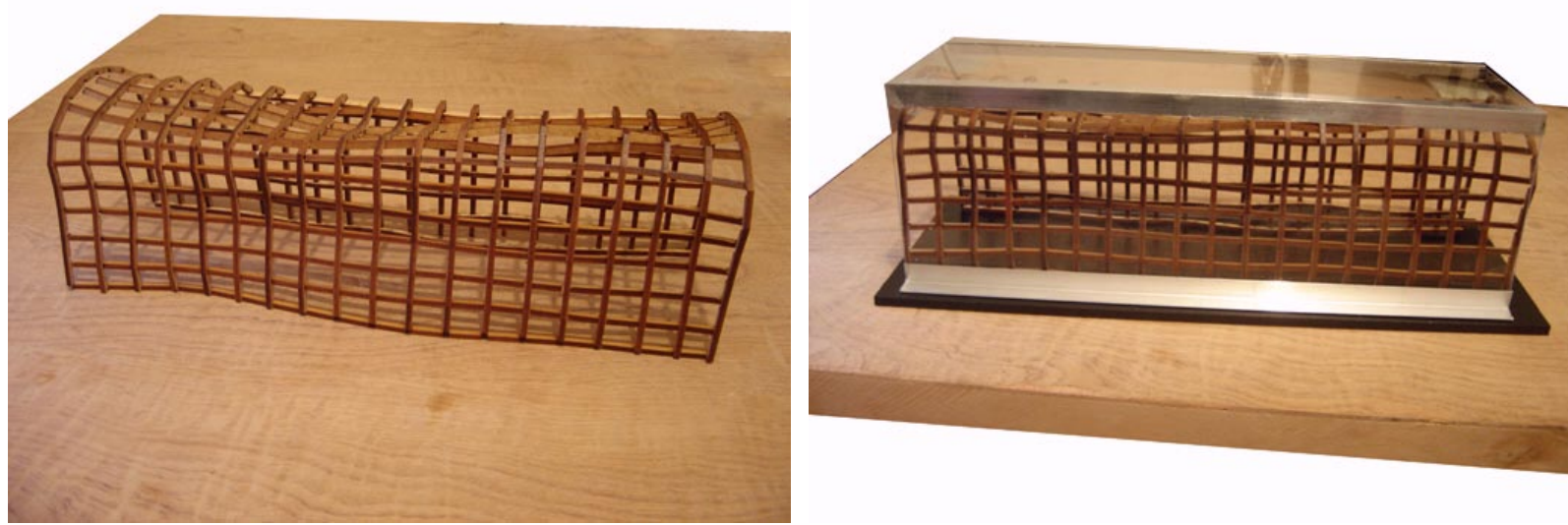

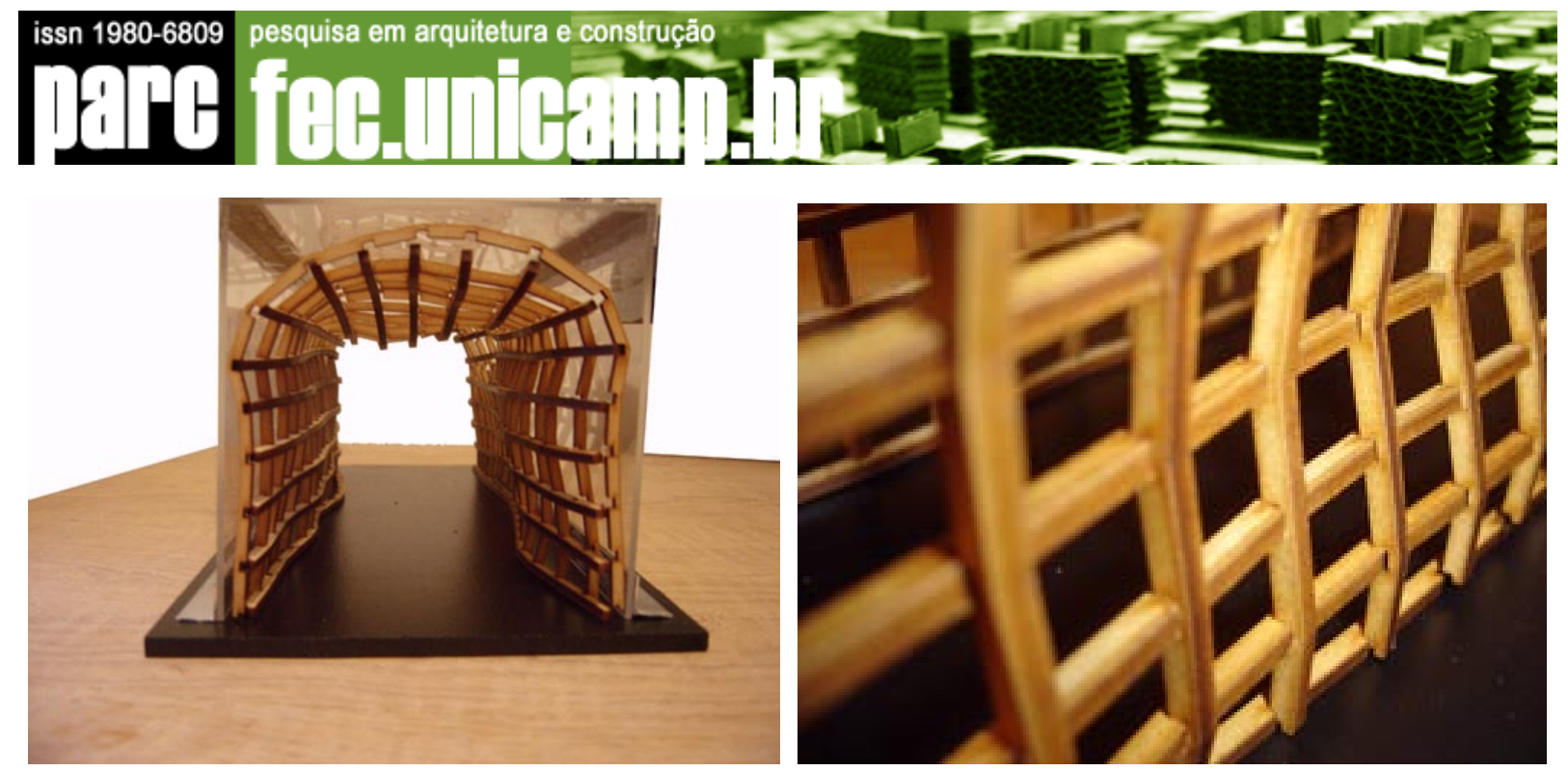

Figura 22, 23, 24 e 25. Estrutura montada, maquete final (vista de lado e frontal) e detalhe das peças da estrutura encaixadas.

\section{Conclusão}

As técnicas de animação, em sua maioria, podem ser aplicadas no desenvolvimento do projeto arquitetônico, mas como especificado neste artigo, há técnicas nas quais o arquiteto possui maior controle sobre a forma gerada, outras nem tanto, ou ainda aquelas em que o nível de dificuldade é bem mais alto que outras. No entanto, muitas técnicas podem ser utilizadas, dependendo apenas da necessidade do arquiteto e do objeto final.

Nota-se também, com esta pesquisa, a importância da aplicação destas técnicas no ensino de projeto por diversos fatores:

- desmistificar o uso de softwares CAD apenas como ferramenta de representação e inserí-los como ferramenta de desenvolvimento de projeto;

- ampliar o conhecimento do estudante com diferentes técnicas projetuais;

- preparar os estudantes para um mercado de trabalho mundial onde já vem sendo utilizadas tais técnicas;

- usar ferramentas de animação como avaliadoras do projeto arquitetônico;

- obter diferentes resultados no projeto de arquitetura, seja no programa arquitetônico, no impacto no sítio, ou na estética do edifício.

Percebe-se então a importância do uso das novas tecnologias na arquitetura, com opiniões de importantes especialistas da área e o desenvolvimento de um pequeno projeto que utilizou algumas técnicas estudadas ao longo de toda a pesquisa. O trabalho descreve 


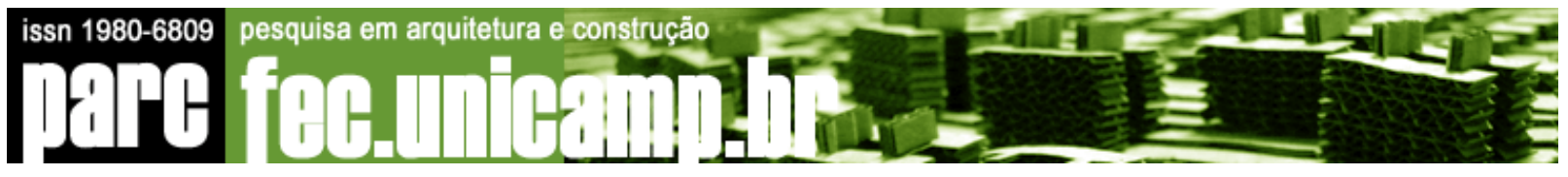

uma metodologia do uso da animação como técnica de geração de formas não apenas conceitualmente, mas com todos os seus detalhes e especificidades técnicas desde a concepção até a construção. Embora se trate de um projeto bastante simples, espera-se que esta metodologia possa vir a ser utilizada por outros arquitetos em seus projetos.

\section{Referências}

AL-ATTILI, Aghlab; ROBLES, Rosa M. M.. Digitising Heritage or Reconstructing Imagination. SIGraDi 2007 - La Comunicación en la Comunidad Visual - [Proceedings of the 11th Iberoamerican Congress of Digital Graphics]. Cidade do México, México, Outubro 2007, pp. 48-53.

BENTON, Sarah. Mediating between Architectural Design Ideation and Development through Digital Technology: Dynamic Animation Toys and Mediation Methods in Designing. Predicting the Future [eCAADe Conference Proceedings]. Frankfurt. Setembro 2007, pp. 253260.

CELANI, Gabriela. eCAADe'23: a busca de novos paradigmas para a geração da forma arquitetônica assistida pelo computador. Vitruvius, DROPS: short cuts arquitetônicos, Drops 13, janeiro 2006. Disponível em: <http://www.vitruvius.com.br/drops/drops13_06.asp>. Acesso em: 18 dezembro 2007.

ESPINA, Jane; RINCÓN, Francisco. Simulación como herramienta de planificación urbana: Plaza Baralt. SIGraDi 2007 - La Comunicación en la Comunidad Visual [Proceedings of the 11th Iberoamerican Congress of Digital Graphics]. Cidade do México, México, Outubro 2007, pp. 364-369.

FEAR, Bob. Architecture + Animation. Architecture Design. London: Wiley Academy, v. 71, no. 2, pp. 17-19, abril 2001.

FRANKEN, Bernhard. For the Joy of Driving. Digital/Real - Blobmeister: first built projects. 1 ed. Birkhäuser Basel, 2001. 256 p.

HENRIQUES, Gonçalo Castro. Entrevista. Mensagem recebida por <ducorradi@gmail.com>. 6 de junho de 2008.

New Digital Procedures through Animation: Brief History and Developments.

Predicting the Future [eCAADe Conference Proceedings]. Frankfurt. Setembro 2007, pp. 269274.

MARK, Earl. Simulating dynamic forces in design with special effects tools. Predicting the Future [eCAADe Conference Proceedings]. Frankfurt. Setembro 2007, pp. 219-226. 


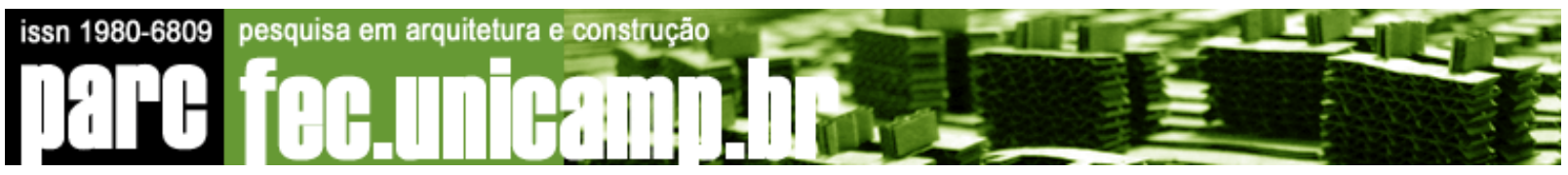

NARAHARA, Taro. Interview. Mensagem recebida por <ducorradi@gmail.com>. 14 de maio de 2008.

Paper - The Space Re-Actor. Mensagem recebida por <ducorradi@gmail.com>. 24 de janeiro de 2008.

. The Space Re-Actor: walking a synthetic man through architectural space. Predicting the Future [eCAADe Conference Proceedings]. Frankfurt. Setembro 2007, pp. 195202.

RAHIM, Ali. ANODYNE, in FEAR, Bob. Architecture + Animation. Architecture Design. London: Wiley Academy, v. 71, no. 2, pp. 17-19, abril 2001.

SCHARRER, Berthold. Interview - escritório de Bernhard Franken. Mensagem recebida por <ducorradi@gmail.com>. 20 de junho de 2008.

SCHMAL, Peter C.; FLAGGE, Ingeborg. Structural Engineering in the Digital Workflow. Digital/Real - Blobmeister: first built projects. 1 ed. Birkhäuser Basel, 2001. 256 p.

SERRATO-COMBE, Antonio. Something's gotta give' architectural animations. SIGraDi 2004 - [Proceedings of the 8th Iberoamerican Congress of Digital Graphics]. Porto Alegre Brasil, novembro 2004, pp. 257-261.

. SAFDE: Sadness, Anger, Fear, Disgust, Enjoyment. Predicting the Future [eCAADe Conference Proceedings]. Frankfurt. Setembro 2007, pp. 237-243.

SOZA, Pedro. Paper - Morfologia Evolutiva. Mensagem recebida por $<$ ducorradi@gmail.com>. 25 de janeiro de 2008.

SOZA, Pedro; COLL, Alejandro Haiek; CADALSO, Eleanna. Modelación por Captura de Movimiento. SIGraDi 2004 - [Proceedings of the 8th Iberoamerican Congress of Digital Graphics]. Porto Alegre - Brasil, novembro 2004, pp. 345-348.

SOZA, Pedro; DOMKE, Andrés Frugone. Morfologia Evolutiva: dos aproximaciones proyectuales. SIGraDi 2007 - La Comunicación en la Comunidad Visual - [Proceedings of the 11th Iberoamerican Congress of Digital Graphics]. Cidade do México, México, Outubro 2007, pp. 107-111.

THEODORE, Dounas. Generative systems based on animation tools: shaping alternatives to structure and form in architectural design. Predicting the Future [eCAADe Conference Proceedings]. Frankfurt. Setembro 2007, pp. 245-251. 


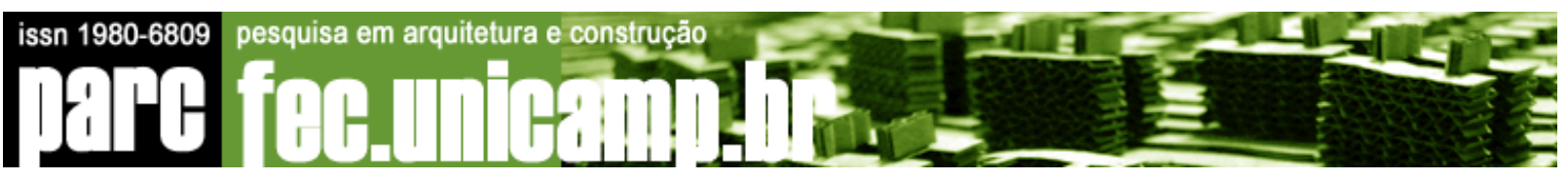

\section{Notas}

${ }^{1}$ Uma animação é formada por vários quadros - ou frames - dependendo do sistema de vídeo utilizado (24 quadros para NTSC; 25 quadros para PAL etc.). Os quadros chaves keyframes - são as imagens que marcam o começo ou fim de uma transição.

2 NURBS (Non Uniform Rational Basis Splines) são modelos matemáticos usados para gerar curvas e superfícies.

3 Os agentes são elementos que possuem todas as informações necessárias para representar as ações humanas que, relacionada à imagem do bípede, nos transmitem a idéia de pessoas reais passeando pelo local.

4 Maxscript é uma linguagem de programação dentro do próprio software 3dsmax, que permite ao usuário criar suas próprias ferramentas, funções, padrões etc.

${ }^{5}$ ASCII (American Standard Code for Information Interchange) é um sistema de codificação de caracteres baseada no alfabeto inglês.

${ }^{6}$ NARAHARA, Taro. The Space Re-Actor: walking a synthetic man through architectural space. Predicting the Future [eCAADe Conference Proceedings]. Frankfurt. Setembro 2007, pp. 195-202.

FRANKEN, Bernhard. For the Joy of Driving. Digital/Real - Blobmeister: first built projects. 1 ed. Birkhäuser Basel, 2001. pp. 184-197.

SOZA, Pedro; DOMKE, Andrés Frugone. Morfologia Evolutiva: dos aproximaciones proyectuales. SIGraDi 2007 - La Comunicación en la Comunidad Visual - [Proceedings of the 11th Iberoamerican Congress of Digital Graphics]. Cidade do México, México, Outubro 2007, pp. 107-111.

${ }^{7}$ Entrevista completa de Gonçalo Castro Henriques em ANEXO. As entrevistas com Berthold Scharrer e Taro Narahara não foram publicadas por não terem sido autorizadas e revisadas pelos entrevistados em tempo hábil para publicação do presente artigo.

${ }^{8}$ www.paracloud.com

\section{ANEXO}

\section{ENTREVISTA GONÇALO CASTRO HENRIQUES}

1. Você poderia citar algumas obras suas que exemplificam o uso da animação no desenvolvimento de projeto? Quais técnicas foram utilizadas?

Vejo a animação como uma forma de expandir as capacidades de concepção ao nosso dispor no projecto . Utilizei "técnicas de animação" nos projectos: Genetic Landscape, Cyber-Eco Fusion e Evolutionary Strategies for Design. O primeiro 


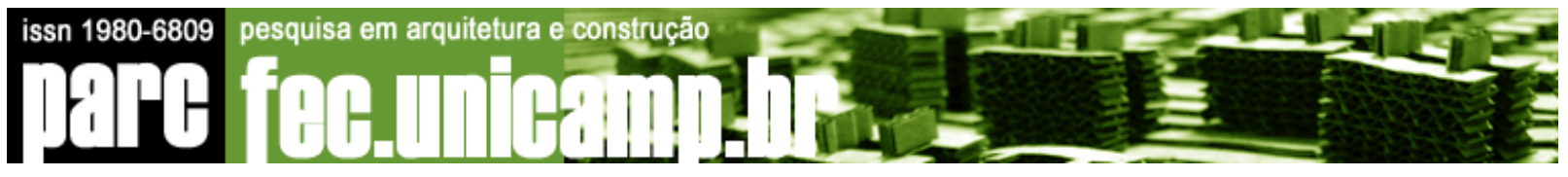

projecto foi construído e os outros dois foram desenvolvidos durante uma investigação de mestrado em Barcelona. Também foram empregues algumas destas técnicas no I Workshop Digital Design Processes, que orientei na ESAP, no Porto em 2006. As técnicas utilizadas são diversas e variam com os projectos, não existindo uma receita prévia.

2. Quais as vantagens em se desenvolver projetos utilizando técnicas de animação em relação às desenvolvidas por métodos tradicionais, ou seja, aqueles que utilizam CAD simplesmente para representação? Quais ideias são possíveis expressar utilizando essas técnicas?

Em termos de validade estas técnicas são tão legitimas como outras que os arquitectos tem ao seu dispor, como por exemplo o desenho à mão livre ou o scripting. A capacidade de as técnicas se tornarem efectivas depende do grau em que a técnica è incorporada e da metodologia utilizada. De outra forma estaríamos a falar do uso de tecnologias. Utilizando as técnicas de animação é possível desenvolver projectos em que a forma é vista como um elemento dinâmico, inserido no tempo e num contexto capaz de a gerar - o que por si só representa uma mudança face à geometria cartesiana mais centrada no problema da representação.

3. Como são vistas essas novas técnicas de desenvolvimento de projecto por críticos de arquitectura, por arquitectos, pela nova geração de estudantes de arquitectura e pelos leigos?

Como as técnicas mais recentes, as que envolvem técnicas de animação, são vistas com desconfiança pelos críticos, mas com entusiasmo pelos estudantes. Enquanto os primeiros criticam as abordagens iniciais mais utópicas - que levaram a que a palavra virtual ganhasse uma conotação negativa e perdesse a relevância que filosoficamente adquiriu. No entanto os estudantes tem uma relação diferente com as tecnologias dos novos "mídias" que fazem já parte do seu dia a dia.

4. Esses projectos que usam essas novas técnicas, como a animação, ainda estão em uma fase experimental ou já podem ser inseridos em um contexto urbano como outros edifícios tradicionais, que seguem a linguagem urbana existente? Quais os impactos deste tipo de projeto na imagem da cidade contemporânea? Existem actualmente alguns exemplos construídos utilizando estas técnicas, que no entanto necessitam de uma visão do conjunto desde a concepção ao fabrico digital para poderem ser concretizáveis. A arquitectura que observamos nas cidades impõe 


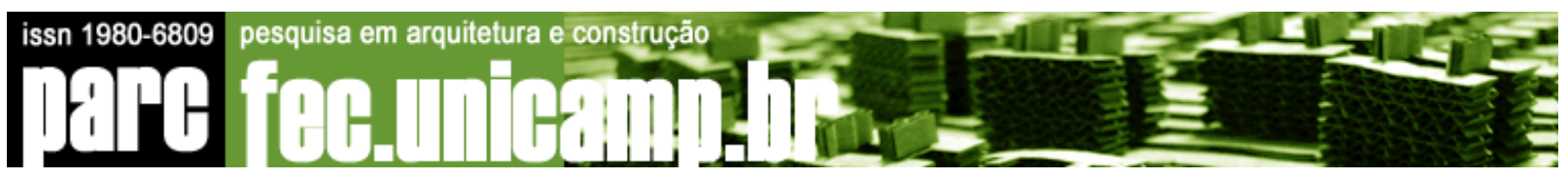

muitas restrições aos usuários -as formas mais livres prometeram trazer uma outra realidade - no entanto poderemos passar de um extremo para outro: ou seja de uma visão pré formatada em modelos (arquitectura modernista) para uma liberdade sem limites ("blob architecture"). É necessário bom senso e sensibilidade para poder analisar a questão nos vários aspectos envolvidos, como seja o social, psicológico, cultural e humano.

5. A tendência da arquitetura dos próximos anos é se apoiar em novas tecnologias para a geração de formas e abandonar aos poucos os métodos mais tradicionais?

De uma forma geral a tecnologia depende do uso que é feito dela; As descobertas científicas podem ser utilizadas com fins humanitários ou para gerar destruição como no caso da teoria da relatividade que foi usada para criar a bomba atómica.

A crença cega na tecnologia como fonte de progresso já teve um preço elevado em muitas situações, como aconteceu no período do modernismo mais ortodoxo.

A seguir a este modernismo mais radical - da tábua rasa - seguiram-se reacções locais num processo que então Kenneth Frampton designou como regionalismo crítico. Esta reacção procurava resposta locais e vernaculares a um fenómeno global.

Estamos num momento em que novas tecnologias prometem grandes avanços e possibilidades, diria um novo progressismo. A tecnologia (também) poderá libertar os artesãos para actividades mais criativas, mas é preciso não esquecer que a tecnologia global necessita de procurar respostas local e de ser integrada com os métodos e a cultura tradicional para poder ser absorvida e transformada.

Gonçalo Castro Henriques (X-Ref | referências cruzadas), Porto 6 Junho 2008 